\title{
Kinetics and Mechanism of Oxidation of Nicotine by Permanganate Ion in Acid Perchlorate Solutions
}

\author{
Ishaq A. Zaafarany \\ Department of Chemistry, Faculty of Applied Sciences \\ Umm Al-Qura University, Makkah Al-Mukarramah 1340 \\ Saudi Arabia Kingdom \\ E-mail: ishaq_zaafarany@hotmail.com
}

\begin{abstract}
The kinetics of permanganate oxidation of nicotine alkaloid in aqueous perchlorate solutions at a constant ionic strength of $1.0 \mathrm{~mol} \mathrm{dm} \mathrm{m}^{-3}$ have been investigated spectrophotometrically. The kinetic results showed first-order kinetics in permanganate and fractional-first-order dependence with respect to nicotine concentration. The influence of hydrogen ion concentrations on the reaction rate showed inverse first-order kinetics in $\left[\mathrm{H}^{+}\right]$where the oxidation rates were increased with decreasing hydrogen ion concentration. A kinetic evidence for the formation of 1:1 complex has been revealed. The ionization constant of nicotine was calculated from the kinetic data and was found to be $9.69 \times 10^{-4} \mathrm{~mol} \mathrm{dm}^{-3}$ at ionic strength of $1.0 \mathrm{~mol} \mathrm{dm}^{-3}$ and $25^{\circ} \mathrm{C}$. The kinetic parameters have been evaluated and a tentative reaction mechanism consistent with the kinetic results is discussed.
\end{abstract}

Keywords: Nicotine, Permanganate, Oxidation, Kinetics, Mechanism, Ionization constant

\section{Introduction}

Nicotine is a highly lipid soluble alkaloid (Pailer M, 1964, p.15 \& Smith L, 1971, p.174) which used effectively on a wide range against aphids, capsids, leaf miners and thrips. It is also used for fumigation of green houses (Larson P, 1964, p.2). Moreover, nicotine is the adductive ingredient in tobacco products that keeps many users hooked (Wang H, 2000, p.1125). However, the great importance of nicotine chemistry which is recognized, the information about the kinetics and mechanistics of nicotine oxidation is scarce. The kinetics of oxidation of many organic (Hassan R, 1991, pp. 2018 \& 605), inorganic (Hassan R, 1988, pp. 601 \& 538) and macromolecules (Hassan R, 2009, pp. 95 \& 184) by permanganate ion as an oxidant has been investigated in more details. However, the oxidation of nicotine by this oxidant was investigated as a tool for spectrophotometric determination of nicotine concentration (Murthy V, 1986, p.78), but no attention was focused to either the kinetics or mechanistics of oxidation.

In view of the above arguments, the present investigation seemed to be of interest in order to shed some light on the mechanistic of oxidation of nicotine with the aim at determining the ionization constant of nicotine, kinetically. Again, some information may be gained on the chemistry of nicotine in aqueous solutions from the results obtained.

\section{Experimental}

\subsection{Materials and Methods}

Potassium permanganate used was of analytical grade (BDH). The preparation and standardization of permanganate solutions were the same as described earlier (Hassan R, 1988, pp. 601 \& 605). Optical density versus concentration plots for acidified $\mathrm{MnO}_{4}^{-}$showed that Beer's law is obeyed at a wavelength of $525 \mathrm{~nm}$ where the molar extinction coefficient is $2250 \pm 25 \mathrm{dm}^{3} \mathrm{~mol}^{-1} \mathrm{~cm}^{-1}$ in good agreement with that reported previously (Hassan R, 1988, pp.601 \& 605).

Solutions of nicotine (Fluka Chemical Reagent) were freshly prepared before each experiment. Doubly distilled conductively water was used in all preparations. The temperature was controlled within $\pm 0.05^{\circ} \mathrm{C}$.

All other reagents employed in the present work were of analytical grade and their solutions were prepared by dissolving the requisite amounts of the sample in doubly distilled water.

The ionic strength of the reaction mixtures was maintained constant at $1.0 \mathrm{~mol} \mathrm{dm}^{-3}$ using $\mathrm{NaClO}_{4}$ as a non -complexing agent. 
All kinetic measurements were performed under pseudo-first-order conditions, where nicotine was present in a large excess over that of $\left[\mathrm{MnO}_{4}^{-}\right]$. The procedure of the kinetic measurements was the same as described earlier (Hassan R, 1988, p.601 \& 605). The course of reaction was followed by recording the decrease in absorbance of $\mathrm{MnO}_{4}{ }^{-}$at its absorption maximum, $525 \mathrm{~nm}$, as a function of time. It was verified that there was no interference from other reagents at this wavelength. The absorption spectra of the reactants and typical traces of the spectral changes are shown in Fig. 1.

\subsection{Polymerization test}

The possibility of formation of free-radicals was examined by adding acrylonitrile to the partially oxidized reaction mixture. The formation of a white precipitate indicates that the reaction proceeds by free-radical mechanism.

\section{Results and Discussion}

\subsection{Stoichiometry}

Reaction mixtures containing a slightly known excess of permanganate over that of nicotine substrate concentration at $\left[\mathrm{H}^{+}\right]=0.5 \mathrm{~mol} \mathrm{dm}$ were equilibrated at room temperature. The unreacted permanganate was estimated periodically until it reached a constant value, i.e. completion of the reaction. Spectrophotometric estimation of the unreacted oxidant revealed that 1 mol of permanganate consumed $1.25 \pm 0.1$ mol of nicotine. Product analyses indicated the formation of nicotinic acid as the oxidation product. No detection of $\mathrm{CO}_{2}$ or $\mathrm{NH}_{3}$ was observed. This result suggest that the stoichiometry of the reaction conforms to the following stoichiometric equation

$$
\begin{gathered}
5 \mathrm{C}_{10} \mathrm{H}_{14} \mathrm{~N}_{2}+4 \mathrm{MnO}_{4}^{-}+17 \mathrm{H}^{+} \longrightarrow \\
5 \mathrm{C}_{6} \mathrm{H}_{5} \mathrm{NO}_{2}+5 \mathrm{C}_{4} \mathrm{H}_{8} \mathrm{O}+5 \mathrm{NH}_{4}^{+}+4 \mathrm{Mn}^{2+}+\mathrm{H}_{2} \mathrm{O}
\end{gathered}
$$

where $\mathrm{C}_{10} \mathrm{H}_{14} \mathrm{~N}_{2}, \mathrm{C}_{6} \mathrm{H}_{5} \mathrm{NO}_{2}$ and $\mathrm{C}_{4} \mathrm{H}_{8} \mathrm{O}$ represent to nicotine, nicotinic acid and butaldehyde, respectively. The formation of nicotinic acid, aldehyde and ammonium ion, were confirmed by spot test (Feigl F,1975,p.290) and IR-spectra. The absence of $\mathrm{CO}_{2}$ and $\mathrm{NH}_{3}$ were confirmed by the tests of pubbling $\mathrm{N}_{2}$ gas through a tube containing lime water and Nessler's reagent, respectively (Vogel A,1978,p.730). The formation of the present products were found to be in good agreement with that reported elsewhere (Murthy V,1986,p.78). The latter species could not be identified under our experimental conditions owing to the low concentration of the substrate used.

\section{$3.2\left[\mathrm{MnO}_{4}^{-}\right]$and [Nicotine] Dependences}

Pseudo-first-order plots of ln (absorbance)-time plots were found to be linear for more than three half-lives of reaction completion. This result indicates that the reaction is first-order with respect to $\left[\mathrm{MnO}_{4}^{-}\right]$. The values of pseudo-first-order rate constants, $k_{o b s}$, were calculated from the gradients of these plots at a variety of initial $\mathrm{MnO}_{4}{ }^{-}$and nicotine concentrations. The first-order dependence was confirmed not only by the observed linearity of the pseudo-first-order plots but also by the independence of the obtained rate constants on different initial concentrations of the oxidant ranging between (1-6) $\times 10^{-4} \mathrm{~mol} \mathrm{dm}^{-3}$.

The non-constancy of the second-order rate constants derived from dividing the observed first-order rate constants by the initial [Nicotine] indicates that the rate is of fractional-order in [Nicotine]. Again, a plot of $1 / k_{o b s}$ against 1/[Nicotine] was found to be linear with a positive intercept on the 1/[Nicotine] axis as shown in Fig. 2. This linearity obeys the Michaelis-Menten kinetics for the formation of 1:1 intermediate complex.

\subsection{Dependence of reaction rate on $\left[\mathrm{H}^{+}\right]$}

To clarify the influence of the $\left[\mathrm{H}^{+}\right]$on the rate of reaction and to elucidate a reaction mechanism, some kinetic measurements were performed at different $\left[\mathrm{H}^{+}\right]$and constant ionic strength and temperature. An increase in acid concentration was found to accompany by a decrease in the observed first-order-rate constant. This means that the reaction is acid-inhibitor. The order with respect to $\left[\mathrm{H}^{+}\right]$was found to be of inverse non-integral order (obtained from $\log k_{o b s^{-}} \log \left[\mathrm{H}^{+}\right]$plots). The results are summarized in Table 1.

In acid solutions, nicotine is usually existed as the protonated form (Peterson E, 2002, p.12662). The inverse-order dependence in $\left[\mathrm{H}^{+}\right]$may be explained by the release of protons from nicotine prior to the rate-determining step.

Again, obeying the oxidation reaction to the Michaelis-Menten kinetics (Fig. 2) with the observed fractional-first order in [Nicotine] may suggest the formation of 1:1 complex between the reactants prior to the rate-determining step. 
In view of the foregoing interpretations and the experimental observations, the most likely reaction mechanism which may be suggested involves the two following equilibria

$$
\begin{gathered}
\mathrm{SH}^{+} \stackrel{K_{1}}{\rightleftharpoons} \mathrm{S}+\mathrm{H}^{+} \\
\mathrm{MnO}_{4}^{-}+\mathrm{H}^{+} \stackrel{K_{2}}{\rightleftharpoons} \mathrm{HMnO}_{4}
\end{gathered}
$$

where $\mathrm{S}$ and $\mathrm{SH}^{+}$denote the nicotine substrate and its protonated form, whereas $K_{l}$ and $K_{2}$ are the ionization and protonation constants of nicotine [(Peterson E, 2002, p.12662) and permanganate ion (Baes C, 1976, p. 224) respectively. Then, the oxidant attacks nicotine substrate to form an intermediate complex $\left(\mathrm{C}_{1}\right)$,

$$
\mathrm{S}+\mathrm{HMnO}_{4}^{-} \stackrel{K_{3}}{\rightleftharpoons} \mathrm{C}_{1}+\mathrm{H}^{+}
$$

followed by fast decomposition of the intermediate $\left(\mathrm{C}_{1}\right)$ in the rate-determining step to give rise to the product via formation of free-radical substrate as expressed by Eq. (5)

$$
\begin{gathered}
\mathrm{C}_{1} \stackrel{k_{1}}{\longrightarrow} \mathrm{Mn}^{\mathrm{VI}} \mathrm{O}_{4}{ }^{2-}+\mathrm{C}_{1} \cdot \\
\mathrm{C}_{1} \cdot \stackrel{\text { fast }}{\longrightarrow} \text { product }
\end{gathered}
$$

where $K_{3}$ is the formation constant of the complex and $k_{l}$ is the first-order rate constant of the complex decomposition in the rate-determining step.

The change of the rate constant with the change in the hydrogen ion and nicotine concentrations can be expressed by the following rate-law expression

$$
\text { Rate }=\frac{-d\left[\mathrm{MnO}_{4}^{-}\right]}{d t}=\frac{k_{1} K_{1} K_{2} K_{3}\left[\mathrm{H}^{+}\right]^{-1}[\mathrm{~S}]_{T}\left[\mathrm{MnO}_{4}^{-}\right]}{1+K_{1}\left[\mathrm{H}^{+}\right]^{-1}+K_{1} K_{2} K_{3}\left[\mathrm{MnO}_{4}^{-}\right]}
$$

where $[\mathrm{S}]_{T}$ represents the analytical total concentration of the substrate. In the presence of a large excess of nicotine over that of permanganate concentration, the rate-law expression is

$$
\text { Rate }=\frac{-d\left[\mathrm{MnO}_{4}^{-}\right]}{d t}=k_{o b s}\left[\mathrm{MnO}_{4}^{-}\right]
$$

Comparing equations (7) and (8) and rearrangement, one concludes that

$$
\frac{1}{k_{\mathrm{o} b s}}=\left(\frac{1+K_{1}\left[\mathrm{H}^{+}\right]^{-1}}{k_{1} K_{1} K_{2} K_{3}\left[\mathrm{H}^{+}\right]^{-1}}\right) \frac{1}{[\mathrm{~S}]_{\mathrm{T}}}+K^{\prime}
$$

Equation (9) requires that, at constant $\left[\mathrm{H}^{+}\right]$plots of $1 / k_{\text {obs }}$ against $1 /[\mathrm{S}]_{T}$ to be linear with positive intercepts on $1 / k_{o b s}$ axis. The experimental results were found to satisfy this requirement as shown in the reciprocal Mechaelis-Menten plot (Fig. 2). Again, plots of $1 / k_{o b s}$ against $\left[\mathrm{H}^{+}\right]$at constant $[\mathrm{S}]$ gave good straight lines with positive intercepts on $1 / k_{o b s}$ axis. The small intercept observed in Fig. 2 may lead us to simplify Eq. (9) to Eq. (10)

$$
\frac{[\mathrm{S}]_{\mathrm{T}}}{k_{\text {obs }}}=\frac{1}{k^{\prime}}=\left(\frac{\left[\mathrm{H}^{+}\right]}{k_{1}{ }^{\prime}}+\frac{1}{k_{1}^{\prime \prime}}\right)
$$

where $k_{1}{ }^{\prime}$ and $k_{1}{ }^{\prime \prime}$ are the apparent rate constants which equal to $k_{1} K_{l} K_{2} K_{3}$ and $k_{1} K_{2} K_{3}$, respectively and $k^{\prime}$ is the second-order rate constant. 
According to Eq. (10), plots of $[\mathrm{S}]_{\mathrm{T}} / k_{o b s}$ vs. $\left[\mathrm{H}^{+}\right]$gave good straight lines with positive intercepts on $[\mathrm{S}]_{\mathrm{T}} / k_{o b s}$ axis as shown in Fig. 3. The values of $k_{l}{ }^{\prime}$ and $k_{l}{ }^{\prime \prime}$ and the ionization constant of the substrate, $K_{l}$, can be evaluated from the slopes and intercepts of those plots. These values were calculated by the least-square method and listed in Table 2. The ionization constant values obtained for nicotine were found to be in good agreement to that reported elsewhere (Peterson E, 2002, p.12662).

Unfortunately, the values of the rate constants of the elementary reaction, $k_{1}$, could not be calculated because of the non-availability of the formation constants, $K_{3}$. Some attempts have been made to calculate the formation constants from the experimental data, but the results were not encouraged. Therefore, the listed values of rate constants are considered to be composite quantities of the products of the rate constant, the formation constant and the protonation constant, respectively.

The activation parameters of the apparent rate constants and the second-order rate constant were calculated from the temperature-dependence of the rate constants by the method of least-squares using the Arrhenius and Eyring equations. These parameters are summarized along with that of the thermodynamic parameters for ionization constant in Table 3.

An alternative reaction mechanism could be suggested. It involves the rapid protonation of the substrate,

$$
\mathrm{S}+\mathrm{H}^{+} \stackrel{K_{4}}{\rightleftharpoons} \mathrm{SH}^{+}
$$

followed by an attack of the oxidant to the positive protonated- substrate to form an intermediate complex $\mathrm{C}_{2}$,

$$
\mathrm{SH}^{+}+\mathrm{MnO}_{4}^{-} \stackrel{K_{5}}{=} \mathrm{C}_{2}+\mathrm{H}^{+}
$$

The formed intermediate $\left(\mathrm{C}_{2}\right)$ is rapidly decomposed in the rate-determining step to give rise to the product through the formation of a free-radical substrate

$$
\begin{gathered}
\mathrm{C}_{2} \stackrel{k_{1}}{\longrightarrow} \mathrm{Mn}^{\mathrm{VI}} \mathrm{O}_{4}{ }^{2-}+\mathrm{C}_{2} \cdot \\
\mathrm{C}_{2} \cdot \stackrel{\text { fast }}{\longrightarrow} \text { product }
\end{gathered}
$$

In a similar manner, the change of the rate constant with the change in $\left[\mathrm{H}^{+}\right]$and $[$Nicotine] will lead to the following relationship

$$
\frac{1}{k_{\mathrm{o} b s}}=\left(\frac{1+K_{4}\left[\mathrm{H}^{+}\right]}{k_{2} K_{4} K_{5}}\right) \frac{1}{[\mathrm{~S}]_{\mathrm{T}}}+K^{\prime \prime}
$$

where $K_{4}$ is the protonation constant of the substrate. This relationship resembles Eq. (8) in which a plot of $1 / k_{o b s}$ against $1 /[\mathrm{S}]_{T}$ at constant $\left[\mathrm{H}^{+}\right]$gave a good straight line with a positive intercept on $1 / k_{o b s}$ axis (Fig. 2 ). The small intercept shown in Fig. 2 may also lead us to simplify Eq. (15) to Eq. (16)

$$
\frac{[S]_{T}}{k_{\text {obs }}}=\left(\frac{1}{k_{2}{ }^{\prime}}+\frac{\left[\mathrm{H}^{+}\right]}{k_{2}{ }^{\prime \prime}}\right)
$$

where $k_{2}{ }^{\prime}=k_{2} K_{4} K_{5}$ and $k_{2}{ }^{\prime \prime}=k_{2} K_{5}$, respectively. According to Eq. (16), plots of the left-hand side against $\left[\mathrm{H}^{+}\right]$ should be linear with positive intercepts on $[\mathrm{S}]_{T} / k_{o b s}$ axis as was experimentally observed. The values of $k_{2}{ }^{\prime}$ and $k_{2}$ " as well as the protonation constant, $K_{4}$, can be evaluated from the slopes and intercepts of those plots. These values were found to be quite similar to that evaluated in the former mechanism where $k_{2}{ }^{\prime}=k_{l}{ }^{\prime \prime}, k_{2}{ }^{\prime \prime}=k_{l}{ }^{\prime}$ and $K_{4}$ $=1 / K_{l}$, respectively. This fact may be considered a good evidence to support the proposed mechanism.

The smaller activation energies obtained in the present work may support the fact that the reaction takes place between ions of different charges or two neutral molecules. Therefore, the electrostatic attraction between the reactants does not need much energy to bring them together in order to form the activated complex.

Since, permanganate ion is a multi-equivalent oxidant, a variety of mechanistics are possible depending on the nature of both the medium and the reactive species (Stewart R, 1965, p.2). The mechanistic approach of some 
reactions involving acidic permanganate as an oxidant has been based on the formation of intermediate complexes (Hassan R, 1991, p.2018) and other results have been interpreted by free-radical mechanisms (Hassan R, 1992, p.661). Again, the mechanism of electron-transfer is sometimes suggested to be of successive one electron-transfer mechanism of outer-sphere type (Moore F, 1975, p.413) or inner-sphere nature (Hicks K, 1971, p.1107). In other redox reactions, a simultaneous two-electron changes in a single step of inner-sphere nature (Hassan R, 1988, p.605) has been suggested. In this context, it should be noticed that there does not appear to be any experimental confirmation of an outer-sphere of two-electron transfer process (Hassan R, 1991, p.3003).

Although the rate-law expression here provides no information about electron transfer process, whether it is of inner- or outer-sphere nature, some information may be expected by examining the magnitudes of the rate constants and the activation parameters (Moore F, 1975, p.413). Unfortunately, no data are available on the formation constants in order to evaluate the rate constants of the principal elementary reactions. Moreover, it noticed that the entropy of activation tends to be more positive for outer-sphere types, whereas the reactions of negative $\Delta S^{\ddagger}$ values are mainly proceeded via inner-sphere mechanism (Hassan R, 1992, p255). The entropy of activation obtained in the present work suggests that the inner-sphere type is the more favorable one for oxidation of nicotine by permanganate ion via free-radical mechanism of one-electron transfer process. A plausible mechanism of oxidation in good consistent with the experimental kinetics may be illustrated by Schemes 1.

\section{Conclusion}

The oxidation of nicotine by potassium permanganate in acid perchlorate solutions have been investigated, spectrophotometrically. The oxidation process was found to proceed through the formation of 1:1 intermediate complex prior to the rate determining step via free radical mechanism. The reaction was found to be acid-inhibition where the oxidation rates were increased with decreasing the hydrogen ion concentration. The kinetic evaluated value of the ionization constant of nicotine was found to be in good agreement with that reported elsewhere. The oxidation product of nicotine was identified as nicotinic acid. A reaction mechanism in good consistent with the kinetic results was suggested and discussed.

\section{References}

Baes C F and Mesmer R E. (1976). The hydrolysis constants, Wiley, New york, p.224 \& Hogfeld Erlic (1st edn)(1982). Stability constants of Metal Ion complexes, Part A Inorganic ligand, Pergamon press, New York, 73.

Fiegl F and Anger V. (1978). Spot tests in organic analysis, Elsevier, Oxford, 290 \& 332.

Hassan R M. (1991). Kinetics of reaction of uranium(IV) of hexachloroiridate(IV) in acid perchlorate solutions. Evidence for a binuclear intermediate, $J$ Chem Soc, 3003-3008.

Hassan R M, Mousa M A and Wahdan M H. (1988). Kinetics and mechanism of oxidation of $\beta$-phenylalanine by permanganate ion in aqueous perchloric acid, J Chem Soc, Dalton Trans , 605-609 \& Hassan R M (1991). Kinetics and mechanism of oxidation of DL- $\alpha$ - alanine by permanganate ion in acid perchlorate media, Cand J Chem, 69, 2018-2023.

Hassan R M, El-Gaiar S A and El-Summan A M. (1993). Kinetics and mechanism of oxidation of selenium(IV) by permanganate ion in aqueous perchlorate solutions. Collect Czech Commun, 58, 538-546.

Hassan R M, Fawzy A, Ahmed G A, Zaafarany I A, Asghar B H and Khairou K S. (2009). Acid catalyzed oxidation of some sulfated macro-molecules. Kinetics and mechanism of permanganate oxidation of kapp-carrageenan polysaccharides in acid perchlorate solutions. J Mol Cat , 309, 95-102 \& Hassan R M, Abdel-Kader D A, Ahmed S M, Fawzy A, Zaafarany I A and Takagi H D (2009). Acid catalyzed oxidation of carboxymethyl cellulose. Kinetics and mechanism of permanganate oxidation of carboxymethyl cellulose in acid perchlorate solutions. Cat commun, 11, 184-190.

Hassan R M, Mousa M A and El-Shatoury S A. (1988). Kinetics of oxidation of uranium(IV) by permanganate ion in aqueous perchlorate media. J Chem Soc, Dalton Trans, 601-603

Hassan R M. (1992). Kinetics and mechanism of oxidation of kojic acid by permanganate ion in perchlorate media. Acta Chem Hungar, 129, 661-669.

Hicks K W and Sutter J R. (1971). Kinetic studies of permanganate oxidation reactions. III. Reactions with tris (1,10-phenanthroline iron(II), J Phys Chem, 76, 1107-1113.

Larson P S, Silvette H. (1964). Medical uses of tobacco (past and present). In von Euler, U.S.Ed. Tobacco alkaloid and related compounds. The Macmillan Co., New York, 2-12. 
Moore F M and Hicks K W. (1975). Mechanism of permanganate oxidation of vanadium(IV), Inorg Chem, 14,413-416.

Murthy V K. (1986). Oxidation of nicotine. Determination of nicotine concentration. Tobacco Res, 12, 78-93.

Pailer M. (1964).Tobacco alkaloid and related compounds, van Euler, U.S. Edn., Macmillan Co., New York, 15-36.

Peterson E J , Choi A, Dahan D S, Lester H A and Dougherty D A. (2002). A Petrubed pKa at the binding site of nicotinic acetylcholine acceptor. Implication for nicotine binding. J Am Chem Soc, 124, 12662-1266.

Smith L O and Cristol S J (West Edn.). (1971). Organic Chemistry, p.174.

Stewart R. (1965). Oxidation by permanganate in Wiberg K B Editor. Oxidation in inorganic chemistry, Academic Press, New York, 2-33.

Vogel A I (4 th Edn). (1978). A text book of quantitative inorganic analysis, EIBS, 730 \& Vogel A I. (1962). Practical organic chemistry, longman, London, 325.

Wang H, Ma L, Li Y and Cho, Ch. (2000). Exposure to cigarette smoke increases apoptosis in the rat gastric mucosa through a reactive oxygen species-mediated and P-35 idependent pathway. Free Radical Biol Med, 28, 1125-1131.

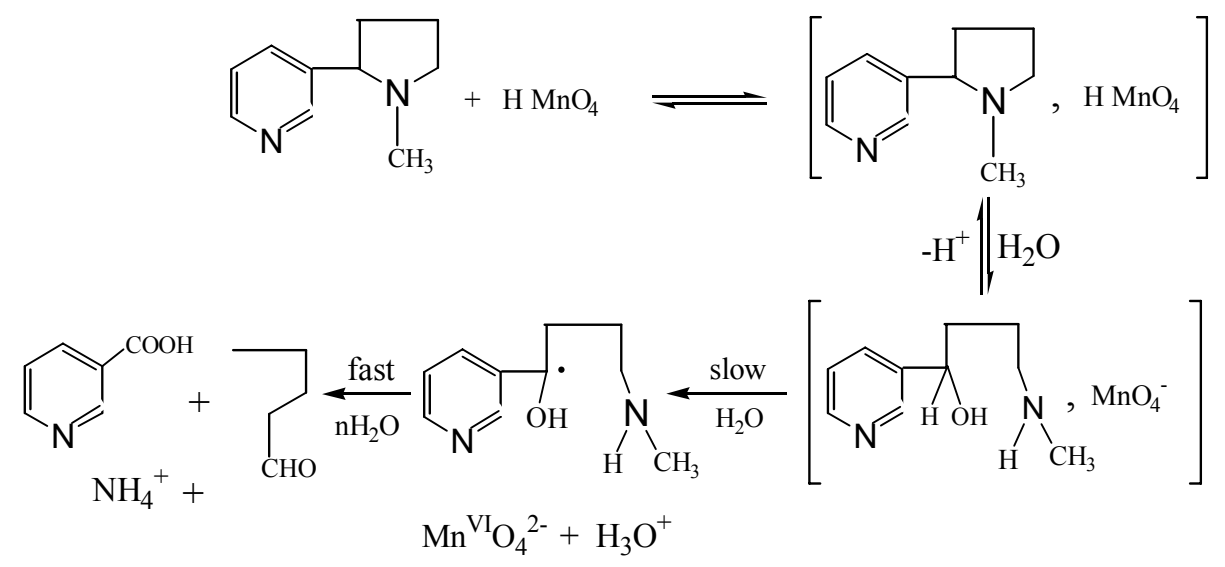

Scheme I

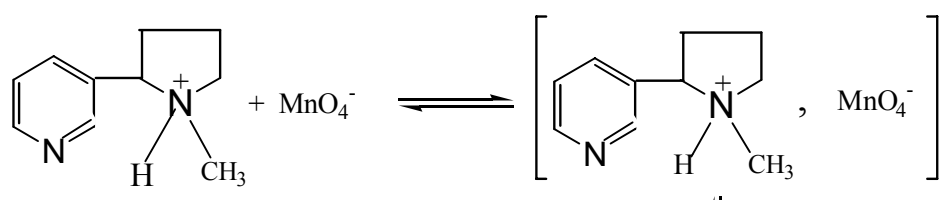$$
-\mathrm{H}^{+} \| \mathrm{H}_{2} \mathrm{O}
$$

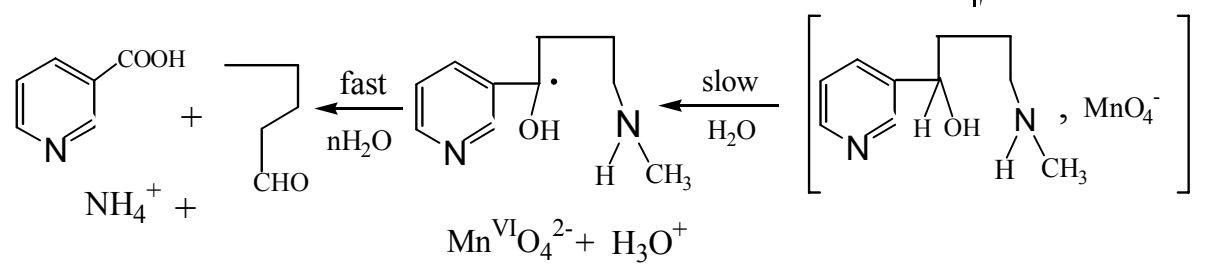

Scheme II 
Table 1. The observed first-order rate constants in the oxidation of nicotine by permanganate ion in aqueous perchlorate solutions. $\left[\mathrm{MnO}_{4}^{-}\right]=4.0 \times 10^{-4},[$ Nicotine $]=1 \times 10^{-2}$ and $\mathrm{I}=1.0 \mathrm{~mol} \mathrm{dm}^{-3}$ at $25^{\circ} \mathrm{C}$

\begin{tabular}{|c|c|c|c|c|}
\hline $10\left[\mathrm{H}^{+}\right], \mathrm{mol} \mathrm{dm}^{-3}$ & 1.25 & 2.50 & 3.75 & 5.00 \\
\hline $10^{3} k_{\text {obs }}, \mathrm{s}^{-1}$ & 4.05 & 2.04 & 1.035 & 1.02 \\
\hline
\end{tabular}

Table 2. The values of the apparent rate constants $\left(k_{l}^{\prime}\right.$ and $\left.k_{l}^{\prime \prime}\right)$ and the ionization constant $\left(K_{l}\right)$ in the oxidation of nicotine by permanganate ion in aqueous perchlorate solutions. $\left[\mathrm{MnO}_{4}^{-}\right]=4 \times 10^{-4}$, $[$ Nicotine $]=1 \times 10^{-2}$ and $\mathrm{I}=$ $1.0 \mathrm{~mol} \mathrm{dm}^{-3}$

Experimental error $\pm 3 \%$

\begin{tabular}{|c|c|c|}
\hline \multirow{2}{*}{ Constant } & \multicolumn{2}{|c|}{ Temperature $\left.\mathbf{(}^{\mathbf{0}} \mathbf{C}\right)$} \\
\cline { 2 - 3 } & 25 & 45 \\
\hline $10^{2} \mathrm{k}_{1}, \mathrm{dm}^{3} \mathrm{~mol}^{-1} \mathrm{~s}^{-1}$ & 5.10 & 8.70 \\
\hline $10^{2} \mathrm{k}_{1}{ }_{1} \mathrm{dm}^{6} \mathrm{~mol}^{-2} \mathrm{~s}^{-1}$ & 0.53 & 2.00 \\
\hline $10^{4} \mathrm{~K}_{1}, \mathrm{~mol} \mathrm{dm}^{-3}$ & 9.69 & 3.48 \\
\hline
\end{tabular}

Table 3. Activation parameters of the apparent rate constants $\left(k_{l}{ }^{\prime}\right.$ and $\left.k_{l}{ }^{\prime \prime}\right)$ and the second-order rate constant $\left(k^{\prime}\right)$ along with that of the thermodynamic parameters of the ionization constant $\left(K_{l}\right)$ in the oxidation of nicotine by permanganate ion in aqueous perchlorate solutions. $\left[\mathrm{MnO}_{4}^{-}\right]=4 \times 10^{-4}$, [Nicotine] $=1 \times 10^{-2}$ and $\mathrm{I}=1.0 \mathrm{~mol} \mathrm{dm}^{-3}$

\begin{tabular}{|c|c|c|c|c|c|}
\hline \multirow[b]{2}{*}{ Constant } & \multicolumn{5}{|c|}{ Parameter } \\
\hline & $\begin{array}{c}\Delta H^{\ddagger} \\
\mathbf{k J} \mathbf{m o l}^{-1}\end{array}$ & $\begin{array}{c}\Delta S^{\ddagger} \\
\mathbf{J} \mathbf{m o l}^{-1} K^{-1}\end{array}$ & $\begin{array}{c}\Delta G^{\neq} \\
\mathrm{kJ} \mathrm{mol}^{-1}\end{array}$ & $\begin{array}{c}E_{a}^{\neq} \\
\mathrm{kJ} \mathrm{mol}^{-1}\end{array}$ & $\begin{array}{c}\text { A } \\
\text { mol }^{-1} \mathbf{s}^{-1}\end{array}$ \\
\hline$k_{1}$, & 19.42 & -204.65 & 80.41 & 22.00 & $2.79 \times 10^{2}$ \\
\hline$k_{1}, "$ & 58.42 & -15.87 & 63.87 & 60.96 & $2.55 \times 10^{12}$ \\
\hline$* \boldsymbol{k}^{\prime}$ & 17.49 & -199.54 & 76.95 & 21.13 & $1.01 \times 10^{3}$ \\
\hline Temp. $\left({ }^{\circ} \mathrm{C}\right)$ & 25 & 35 & 45 & 55 & \\
\hline$K \times 10^{4}$ & 9.69 & 5.48 & 3.48 & 2.28 & \\
\hline Parameter & $\begin{array}{c}\Delta H^{o} \\
\mathrm{KJ} \mathrm{mol}^{-1} \\
\end{array}$ & $\begin{array}{c}\Delta S^{o}{ }_{298} \\
\mathrm{~J} \mathrm{~mol}^{-1} \mathbf{K}^{-1} \\
\end{array}$ & $\begin{array}{c}\Delta G^{o}{ }_{298} \\
\mathrm{~kJ} \mathrm{~mol}^{-1} \\
\end{array}$ & & \\
\hline Value & -39.014 & -188.61 & 17.19 & & \\
\hline
\end{tabular}

* At $\left[\mathrm{H}^{+}\right]=0.25 \mathrm{~mol} \mathrm{dm}^{-3}$

Experimental error $\pm 4 \%$ 


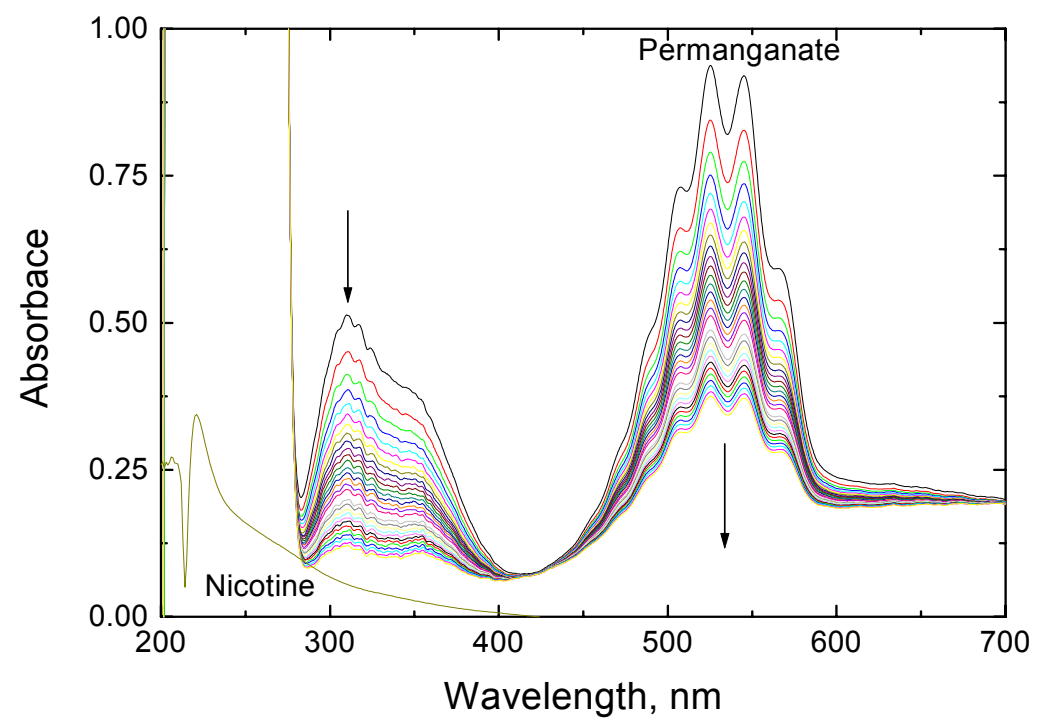

Figure 1. Spectral changes $(200-600 \mathrm{~nm})$ in the oxidation of nicotine by permanganate ion in aqueous perchlorate solutions. $\left[\mathrm{MnO}_{4}^{-}\right]=4 \times 10^{-4}$, $[$ Nicotine $]=1 \times 10^{-2}$ and $\mathrm{I}=1.0 \mathrm{~mol} \mathrm{dm}^{-3}$ at $25^{\circ} \mathrm{C}$. Scanning time intervals 2 min

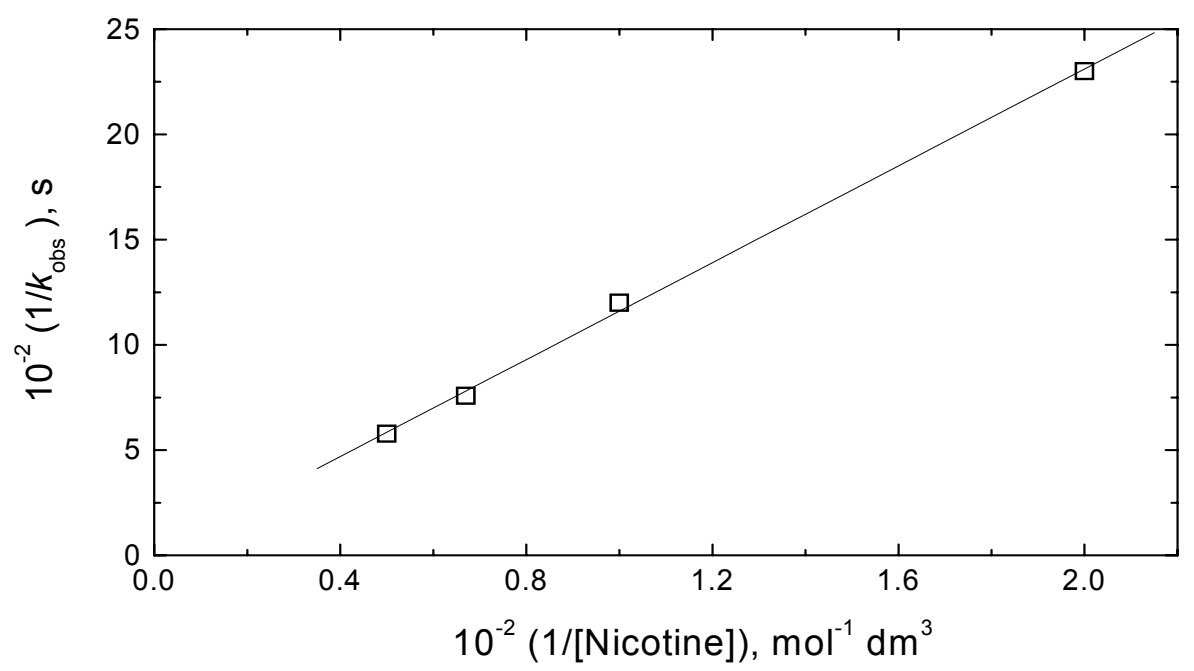

Figure 2. Michaelis-Menten plot in the oxidation of nicotine by permanganate ion in aqueous perchlorate solutions. $\left[\mathrm{MnO}_{4}^{-}\right]=4.0 \times 10^{-4}$, $[$ Nicotine $]=1 \times 10^{-2}$ and $\mathrm{I}=1.0 \mathrm{~mol} \mathrm{dm}^{-3}$ at $25^{\circ} \mathrm{C}$.

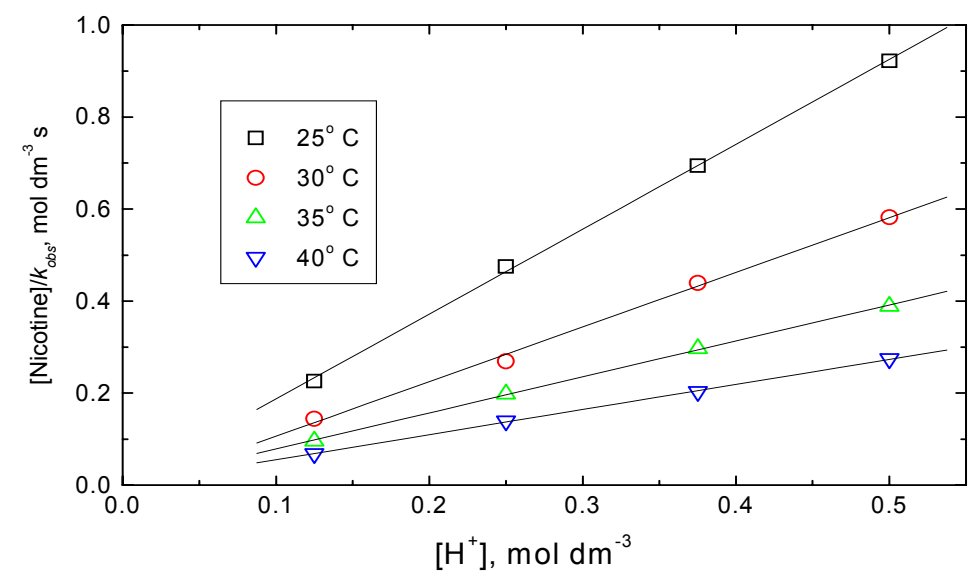

Figure 3. Plots of [Nicotine $] / k_{o b s} \mathrm{vs.}\left[\mathrm{H}^{+}\right]$in the oxidation of nicotine by permanganate ion in aqueous perchlorate solutions. $\left[\mathrm{MnO}_{4}^{-}\right]=4 \times 10^{-4}$, $[$ Nicotine $]=1 \times 10^{-2}$ and $\mathrm{I}=1.0 \mathrm{~mol} \mathrm{dm}^{-3}$ 